\title{
Pesquisas nacionais em ensino de ciências e o pensamento crítico: uma pesquisa bibliográfica
}

National research in science teaching and critical thinking:

a bibliographic research

\author{
Investigaciones nacionales en enseñanza de ciencias
}

y el pensamiento crítico: una investigación bibliográfica

Geislana Padeti Ferreira Duminelli

Universidade Estadual de Maringá (UEM), Maringá/PR - Brasil

Luciano Carvalhais Gomes

Universidade Estadual de Maringá (UEM), Maringá/PR - Brasil

Linnyer Beatrys Ruiz Aylon

Universidade Estadual de Maringá (UEM), Maringá/PR - Brasil

\section{Resumo}

Em 1996, foi promulgada a mais nova Lei de Diretrizes e Bases da Educação Nacional. Dentre os seus artigos, vale destacar o de número 35, que, além de garantir uma identidade ao ensino médio, como etapa final da educação básica, estabelece o desenvolvimento do pensamento crítico como uma finalidade para esse nível de ensino. Desse modo, o principal objetivo deste artigo é apresentar, por meio de uma pesquisa bibliográfica, quais são os procedimentos metodológicos mais utilizados nas pesquisas nacionais, no ensino de ciências, que têm por objetivo mobilizar as capacidades de pensamento crítico dos alunos. Ao final, após uma análise crítica e reflexiva, destacamos que: a) a metodologia privilegiada por esses trabalhos é a proposta por Tenreiro-Vieira (1994); e b) esses trabalhos não contemplam, de modo adequado, em suas reflexões, o importante papel exercido pela postura epistemológica do professor ao elaborar e aplicar as estratégias didático-pedagógicas na mobilização e promoção do pensamento crítico.

Palavras-chave: Ensino de ciências, Pensamento crítico, Construtivismo

\begin{abstract}
In 1996, it was enacted the newest National Education Guidelines and Bases Law. Among its articles, it is worth highlighting the number 35 . In addition to guaranteeing an identity for high school, as the final stage of Basic Education, it establishes the development of critical thinking as a goal for this education level. Through a bibliographic search, this article aims to present the most used methodological procedures in national research in science teaching, aiming mobilize students' critical thinking skills. After a critical and reflective analysis, we highlight that: a) the privileged methodology for these works is the one proposed by Tenreiro-Vieira (1994); and b) these works do not contemplate adequately, in their reflections, the important role played by the epistemological posture of the teacher when elaborating and applying didactic-pedagogical strategies in mobilizing and promoting critical thinking.
\end{abstract}

Keywords: Science teaching, Critical thinking, Constructivism 


\section{Resumen}

En 1996, se promulgó la más reciente Ley de Directrices Base de la Educación Nacional. Entre sus artículos, cabe destacar el del número 35, que, además de garantizar una identidad para el Bachillerato, como etapa final de la Educación Básica, establece el desarrollo del pensamiento crítico como fin de este nivel educativo. Así, el objetivo principal de este artículo es presentar, a través de una búsqueda bibliográfica, cuáles son los procedimientos metodológicos más utilizados en las investigaciones nacionales, en la enseñanza de las Ciencias, que tienen como objetivo movilizar las habilidades de pensamiento crítico de los alumnos. Al final, luego de un análisis crítico y reflexivo, destacamos que: a) la metodología privilegiada por esos trabajos es la propuesta por Tenreiro-Vieira (1994); y b) esos trabajos no contemplan adecuadamente, en sus reflexiones, el importante papel que juega la postura epistemológica del docente a la hora de elaborar y aplicar estrategias didáctico-pedagógicas en la movilización y promoción del pensamiento crítico.

Palavras-chave: Enseñanza de las Ciencias, Pensamiento crítico, Constructivismo

\section{Introdução}

Em 1996, foi promulgada a mais nova Lei de Diretrizes e Bases da Educação Nacional (LDB). Dentre os seus artigos, vale destacar o de número 35 que, além de garantir uma identidade ao ensino médio, como sendo a etapa final da educação básica, estabelece como sendo uma das suas finalidades "[...] o aprimoramento do educando como pessoa humana, incluindo a formação ética e o desenvolvimento da autonomia intelectual e do pensamento crítico [...]" (BRASIL, 2017, p. 24-25, grifo nosso). Dessa forma, começaram a surgir várias pesquisas na área de ensino de ciências, alegando que as estratégias didático-pedagógicas escolhidas conseguiram desenvolver o pensamento crítico dos alunos.

Contudo, ao aprofundarmos a leitura sobre esses trabalhos, notamos que, apesar do reconhecimento da importância do pensamento crítico, há uma notável falta de consenso sobre a sua definição e avaliação. Corroborando essa nossa afirmação, temos o trabalho de Bordoni et al. (2017), que teve como objetivo "[...] investigar nos anais do X Enpec [Encontro Nacional de Pesquisa em Educação em Ciências] o contexto de discussão do termo Pensamento Crítico" (p. 2). Ao final, os autores chegaram à seguinte conclusão:

[...] que este termo ainda é utilizado de forma pouco compreendida. Sem maior problematização e conscientização de seus aportes teóricos. Podemos afirmar que o uso do mesmo vem se configurando como mais um "slogan" na Educação em Ciências, como tantos outros que já observamos ao longo das décadas [...]. (BORDONI et al., 2017, p. 7, grifo nosso) 
Guiados por essas reflexões, percebemos que, para planejarmos uma estratégia didático-pedagógica para ensinar física no ensino médio, com o auxílio da robótica, e favorecer o desenvolvimento do pensamento crítico dos alunos, teríamos que responder o seguinte problema de pesquisa: Quais são os procedimentos metodológicos mais utilizados nas pesquisas nacionais, no ensino de ciências, que têm por objetivo mobilizar às capacidades de pensamento crítico dos alunos? Assim, o principal objetivo deste artigo é mostrar qual a metodologia que utilizamos para responder à essa indagação e apresentar, por meio de uma análise crítica e reflexiva, os resultados que encontramos.

\section{Procedimentos metodológicos}

Para nortear o nosso percurso metodológico, utilizamos os procedimentos da pesquisa bibliográfica que foram delineados por Salvador (1981), ao dividi-la em quatro fases principais: elaboração do projeto de pesquisa, a investigação das soluções, a análise explicativa das soluções e a síntese integradora. Embora o autor esteja se referindo ao projeto como um todo, essas fases também são aplicáveis para responder ao nosso problema de pesquisa.

Assim, começamos realizando uma procura no portal da Biblioteca Digital Brasileira de Teses e Dissertações (BDTD) utilizando os seguintes termos de busca: Todos os campos: "pensamento crítico" e Todos os campos: "ensino de ciências". A busca foi realizada em novembro de 2020, e não estipulamos filtro. Obtivemos o retorno de 60 trabalhos. Como não era a nossa intenção fazer um estado da arte do tema, realizamos uma leitura de reconhecimento pelos resumos para tentar identificar quais textos eram os mais representativos da amostra.

Percebemos que, na maioria dos resumos, o termo pensamento crítico aparece apenas como uma reflexão filosófica, palavras impactantes, sem uma preocupação de defini-lo ou de discutir critérios para elaborar e avaliar práticas didático-pedagógicas mobilizadoras das capacidades de pensamento crítico.

Por exemplo, em um dos resumos analisados, Silva (2017), tem-se a seguinte declaração: "[...] a maioria dos estudantes afirmou que o trabalho com o PBL [Problem Based Learning] favoreceu o pensamento crítico, que os aproximou do cenário escolar como professor [...]". Ora, essa percepção dos estudantes, de que a atividade favoreceu o pensamento crítico, pode até ser considerada como um fator 
positivo no quesito engajamento ou motivação, mas a autora não apresentou nenhum critério para avaliar qual a possibilidade de isso ter ocorrido realmente.

Além desses casos, também constatamos que, em muitos resumos, o termo pensamento crítico sequer estava presente, julgamos que foi incluído apenas no campo "assunto", quando da inclusão do trabalho no portal da BDTD. Por outro lado, notamos que os textos que apresentavam o termo pensamento crítico em seus títulos eram os que tinham os perfis de resumo que mais nos interessavam. Dessa forma, realizamos uma nova procura no portal com os seguintes termos de busca: Título: "pensamento crítico" e Todos os campos: "ensino de ciências". A busca foi realizada em novembro de 2020, e não estipulamos filtro. Obtivemos sete trabalhos que serão discutidos, sinteticamente, na quarta seção deste artigo, são eles: Barreto (2019); Bertoldo (2018); Santana (2018); Santana (2019); Santiago (2018); Santos (2018); e Souza (2019).

Na sequência, realizamos uma leitura rápida, flutuante, de cada material, cujo objetivo foi verificar se realmente eram os mais representativos da amostra, o que foi confirmado. Logo, eles foram os escolhidos para uma leitura mais reflexiva, crítica e interpretativa. A partir desses sete textos, também selecionamos alguns livros e artigos que foram referenciados pelos autores e nos atraíram o interesse para uma análise de seus conteúdos na íntegra, bem como outros trabalhos que nos auxiliaram a fazer uma análise crítica e reflexiva desses materiais, seguindo as recomendações de Salvador (1981), para cada uma das fases de uma pesquisa bibliográfica.

\section{Pensamento crítico: uma visão geral}

$\mathrm{Na}$ área da educação, na atualidade, Robert Hugh Ennis ${ }^{1}$ é considerado o teórico sobre pensamento crítico mais influente, "[...] ao ponto de ser a sua teorização que progressivamente se impôs [...]" (TENREIRO-VIEIRA; VIEIRA, 2000, p. 27). Em muitos de seus artigos, o termo pensamento crítico é definido como uma forma de pensamento racional, reflexivo, focado naquilo em que se deve acreditar ou fazer (ENNIS, 1985; 1987; 2013). Além disso, Ennis (1985; 1987; 2013) esclarece que, ao ter que decidir no que acreditar ou fazer, o sujeito deve usar um conjunto de habilidades e disposições. Com a intenção de identificar e enumerar algumas dessas

\footnotetext{
1 Professor emérito da Faculdade de Educação da Universidade de Illinois. Em 2020, completou 93
} anos, sendo mais de 60 dedicados às pesquisas relacionadas com a temática do pensamento crítico.

Revista Educação Online, Rio de Janeiro, n. 37, mai-ago 2021, p. 137-152 
habilidades e disposições, que seriam importantes de serem desenvolvidas na escola, Ennis $(1985,1987)$ propôs uma taxonomia intitulada "Metas para um Currículo de Pensamento Crítico". Pela limitação de espaço do artigo, não será possível apresentá-la aqui na íntegra. Contudo, há uma versão traduzida para o português, que pode ser consultada, em sua totalidade, em Tenreiro-Vieira (2000).

Essa taxonomia está dividida em duas grandes categorias: disposições e capacidades. Nas disposições, são elencados quatorze itens, relacionados aos aspectos afetivos, que o sujeito deve ter para decidir, de modo racional e reflexivo, em que acreditar ou fazer, tais como: tentar estar bem-informado; utilizar e mencionar fontes credíveis; tentar não se desviar do cerne da questão; etc. $A$ categoria das capacidades, relacionada aos aspectos cognitivos, é dividida, por sua vez, em cinco subcategorias: clarificação elementar; suporte básico; inferência; clarificação elaborada e estratégias e tácticas. Em cada uma dessas subcategorias, estão dispostos alguns itens (capacidades) e subitens (descritores). A taxonomia proposta por Ennis $(1985$; 1987) pode ser considerada como uma definição operacional para pensamento crítico, pois

[...] é um procedimento que atribui um significado comunicável a um conceito através da especificação de como o conceito é aplicado dentro de um conjunto específico de circunstâncias. De uma outra forma, uma definição operacional é uma descrição precisa de o que algo é e de como se obtém um valor para esse algo que estamos tentando medir, ou seja, de como medi-lo. Uma definição operacional tem que ser específica, concreta, mensurável e útil para as pessoas envolvidas. (PINHEIRO, 2020, p. 1)

Devido ao fato de ela ser específica, concreta e mensurável, começou a ser utilizada como "[...] um instrumento de trabalho para o desenvolvimento de actividades, focadas em conteúdos de ciências, promotoras do Pensamento Crítico" (TENREIRO-VIEIRA, 2000, p. 58). Todos os sete trabalhos nacionais sobre pensamento crítico que selecionamos para analisar utilizaram, de algum modo, a taxonomia de Ennis $(1985,1987)$ em suas metodologias de pesquisa. $O$ que corrobora o seu potencial metodológico para auxiliar a compreensão das capacidades de pensamento crítico relacionadas aos processos de ensino e aprendizagem dos conceitos científicos. Vejamos, a seguir, uma análise crítica e reflexiva dessas pesquisas. 


\section{Análise crítica e reflexiva}

Podemos resumir as principais características dos sete trabalhos que analisamos, dizendo que todas as pesquisas se apoiaram na definição operacional de pensamento crítico de Robert Hugh Ennis e em sua taxonomia. O trabalho de Bertoldo (2018) foi o único que não estava relacionado com o componente curricular de química do ensino médio. Os trabalhos de Santana (2018) e Santana (2019) foram os únicos que não foram realizados em sala de aula. Dos cinco trabalhos que foram executados em sala de aula, apenas Bertoldo (2018) elaborou e ministrou as suas próprias intervenções didáticas (rodas de conversa).

Os outros quatro foram bolsistas do Programa Institucional de Bolsas de Iniciação à Docência (Pibid) de química, que ministraram as atividades didáticopedagógicas, tais como: oficinas temáticas, jogo simulador de papéis, abordagem Ciência-Tecnologia-Sociedade (CTS), ensino por investigação etc. Dos cinco trabalhos que envolveram estratégias de ensino, apenas Bertoldo (2018) não utilizou os três momentos pedagógicos de Delizoicov, Angoti e Pernambuco (2002) para nortear o planejamento e a execução da atividade didático-pedagógica aplicada em sala de aula.

Em todas as cinco pesquisas realizadas no ambiente escolar, as capacidades de pensamento crítico mais mobilizadas nos alunos, pelas atividades, foram: 1. Focar uma questão (clarificação elementar); 2. Analisar argumentos (clarificação elementar); e 3. Fazer e responder questões de clarificação e ou desafio (clarificação elementar).

Um fato importante a ser ressaltado é que fica subentendido, ao longo dos textos, uma parceria, a partir de estágios de pós-doutoramento, entre professores da área de ensino de química com os pesquisadores Celina Tenreiro Vieira e Rui Marques Vieira, professores e investigadores sobre a mobilização e promoção do pensamento crítico no Centro de Investigação Didática e Tecnologia na Formação de Formadores da Universidade de Aveiro, em Portugal. Essa parceria justifica o elevado número de pesquisas voltado para o componente curricular de química e o fato de que, resumidamente, cada um dos cinco trabalhos que tiveram aplicações didáticas ter seguido, com pequenas diferenças entre eles, a mesma metodologia que foi testada e proposta por 
Tenreiro-Vieira (1994). Segundo Tenreiro-Vieira e Vieira (2000, p. 38, grifo nosso), ela pode ser usada para

[...] conceber e desenvolver materiais curriculares e/ou atividades de aprendizagem bem como para reformular actividades, materiais ou ambos, habitualmente usados pelos professores. Quando aplicada a materiais curriculares (em particular aqueles que se encontram sob a forma escrita como as fichas de trabalho), a atividades de aprendizagem, ou a ambos, habitualmente usados pelo professor, a metodologia sugerida envolve três fases. Nas duas primeiras, a taxonomia de Ennis é usada como referencial teórico a fim de analisar esses materiais curriculares e/ou atividades de aprendizagem, por forma a: (i) identificar as capacidades de pensamento crítico a que os mesmos apelam e (ii) identificar outras capacidades de pensamento crítico que possam ser exigidas. Na terceira fase, a taxonomia de Ennis é usada como um modelo ou padrão por forma a explicitar as capacidades de pensamento crítico que podem ser exigidas, escrevendo itens com base em propostas concretas encontradas na própria taxonomia [...]

Desse modo, esse foi o percurso metodológico escolhido pelos trabalhos, com a inclusão de uma quarta fase, mais voltada para uma pesquisa acadêmica, ficando assim: 1) por meio de uma revisão da literatura, verificar os principais objetivos a serem atingidos pelo objeto de estudo (atividades investigativas; abordagem Ciência-Tecnologia-Sociedade (CTS); história da ciência; etc.); 2) inferir, a partir desses objetivos e da taxonomia de Ennis (1985; 1987), quais capacidades de pensamento crítico o objeto de estudo pode apelar; 3) com o auxílio da taxonomia de Ennis (1985; 1987), verificar, principalmente nas questões do material didático elaborado, quais capacidades de pensamento crítico podem ser mobilizadas; 4) verificar, com o auxílio da taxonomia de Ennis (1985; 1987) e da Análise de Conteúdo de Bardin (1977), após a aplicação da atividade didática, quais capacidades de pensamento crítico os alunos, de fato, manifestaram ao longo das estratégias didático-pedagógicas ministradas.

Após essa visão geral, focaremos, doravante, em algumas reflexões que nos chamaram mais atenção, ao longo de uma leitura mais crítica e interpretativa desses textos. Comecemos com Santos (2018), que chegou à conclusão de que as questões do material didático que seria aplicado não tinham o potencial de ir além das capacidades de pensamento crítico classificadas como "Clarificação Elementar". A partir disso, fez a seguinte observação sobre esse resultado:

[...] É importante esclarecer que o material didático, objeto de estudo, não foi pensado para o Pensamento Crítico e que a não percepção de apelo às Capacidades nas demais áreas não se resume em um problema no processo de ensino-aprendizagem. (SANTOS, 2018, p. 57) 
Não fica claro o que o autor quis dizer com "[...] a não percepção de apelo às Capacidades nas demais áreas não se resume em um problema no processo de ensino-aprendizagem", pois ele não ampliou o raciocínio na sequência. A nosso ver, é uma utopia querer que um único material didático dê conta de todas as capacidades estipuladas na taxonomia de Ennis $(1985,1987)$, mesmo sendo "pensado para o Pensamento Crítico". Compreendemos essas capacidades como metas a serem atingidas ao longo de todo o percurso educativo do sujeito, em um grau crescente de intensidade e se respeitando os níveis cognitivos das diferentes faixas etárias. Afinal, o nível de intensidade que se espera da capacidade de "analisar argumentos" de um aluno, com treze anos de idade, que cursa o nono ano do ensino fundamental, não é o mesmo que se almeja para um universitário, com vinte e dois anos de idade, de um curso de física, por exemplo. Nessa óptica, defendemos a abordagem da infusão do pensamento crítico nos conteúdos curriculares, conforme esclarece Tenreiro-Vieira e Vieira (2000, p. 31):

[...] A abordagem da infusão do pensamento crítico nos conteúdos curriculares preconiza que o ensino do pensamento crítico deve ser inserido no contexto de cada uma das disciplinas do currículo por forma a que as capacidades de pensamento crítico sejam infundidas ou entrosadas nos conteúdos da disciplina.

Dessa maneira, devido às inúmeras variáveis que interferem nos processos de ensino e aprendizagem, como a questão da carga horária versus conteúdos curriculares, o apelo às todas as capacidades estipuladas na taxonomia de Ennis $(1985,1987)$ não deve ser responsabilidade exclusiva de um único componente curricular e, muito menos, de somente uma atividade didática. Por outro lado, com esse diagnóstico, espera-se que o docente se sinta desafiado a pensar em outras estratégias didático-pedagógicas, mesmo que seja para diferentes conteúdos da disciplina, para ampliar, o máximo possível, o nível das capacidades mobilizadas e apelar para as demais que não foram manifestadas. Consideramos ser essa a principal vantagem do uso da taxonomia proposta por Ennis.

Voltando ao trabalho de Santos (2018), o último passo de seu caminho metodológico foi a análise da proposta didática durante a sua aplicação. Ao 
comentar sobre o engajamento dos alunos de duas turmas, em específico, o autor afirmou que

[...] no que diz respeito ao engajamento dos alunos, sua grande maioria não se manifestavam [sic], e a falta de diálogo em uma Atividade Investigativa é um grande problema, uma vez que, sabe-se que o papel do professor é guiar os alunos, para que estes levantem suas hipóteses, teste-as e construam o conhecimento, se não há o mínimo de interação professor-aluno, consequente, a atividade de cunho investigativo ganha no seu processo certos dilemas. (SANTOS, 2018, p. 61, grifo nosso)

Pela sua reflexão, o autor dá a entender que a falta de engajamento dos alunos dessas turmas teve a ver, de algum modo, com o hábito adquirido de uma interação inadequada entre o professor de química das turmas e seus alunos, que se reproduziu entre bolsistas-alunos. Isso nos faz ressaltar o cuidado que temos quando nos referimos à potencialidade de uma estratégia didático-pedagógica desenvolver esta ou aquela capacidade de pensamento crítico. Temos conhecimento de que há inúmeras variáveis que podem interferir na concretização dessa potencialidade. Por exemplo, se quem está aplicando a atividade conseguiu construir, adequadamente, as nove necessidades formativas para os professores de ciências, elencadas por Carvalho e Gil-Pérez (2011), a saber: romper com visões simplistas sobre o ensino de ciências; conhecer a matéria a ser ensinada; questionar as ideias docentes de senso comum sobre o ensino e aprendizagem das ciências; adquirir conhecimentos teóricos sobre a aprendizagem das ciências; saber analisar criticamente o ensino tradicional; saber preparar atividades capazes de gerar uma aprendizagem efetiva; saber dirigir o trabalho dos alunos; saber avaliar; adquirir a formação necessária para associar ensino e pesquisa didática. Nessa linha de raciocínio, gostaríamos de tecer alguns comentários sobre a seguinte declaração de Barreto (2019, p. 37, grifo nosso):

Ressaltamos que para mobilizar estas Capacidades do Pensamento Crítico, é necessário que o material seja construído intencionalmente, ou seja, que o objetivo do material seja mobilizar a ou as capacidades. Para isso, se torna necessário que o material expresse a capacidade. Tenreiro-Vieira e Vieira (2000) destacam que esses materiais devem ser confiáveis e passíveis de serem usados pelos professores em sala de aula, já que a generalidade dos materiais curriculares propostos e comercializados refletem um grande interesse em cumprir primorosamente com os conteúdos pragmáticos de uma maneira em que as questões inerentes nestas matérias [sic] são pouco contribuintes para o Pensamento Crítico. 
Se levarmos essa afirmação até às últimas consequências, chegaremos à uma conclusão precipitada, e errônea, de que praticamente todas as pesquisas realizadas na área de ensino de ciências, até hoje, não conseguiram mobilizar nenhuma capacidade do pensamento crítico. Afinal, como vimos em nossa busca pelas produções nacionais referentes à promoção do pensamento crítico, no ensino de ciências, é ínfima a quantidade de pesquisas que utilizou de estratégias didáticos-pedagógicas construídas intencionalmente para mobilizar essas capacidades. Essa escassez também foi confirmada no trabalho de Boszko e Güllich (2019) e, no contexto de Portugal, por Sousa e Vieira (2018).

Em um outro extremo, corre-se o risco de acreditar que todas as atividades didáticas preparadas intencionalmente para desenvolver as capacidades de pensamento crítico terão, inevitavelmente, êxitos. Temos que tomar o cuidado para não "[...] sucumbir à magia dos métodos e das técnicas [...]" (MINAYO, 2000, p. 197). Vale relembrar aqui as nove necessidades formativas elencadas por Carvalho e GilPérez (2011) e trazer a seguinte reflexão de Gil-Pérez et al. (2005, p. 116, grifo nosso):

[...] não é possível mudar o que normalmente os professores fazem na sala de aula (a simples transmissão de saberes já elaborados) sem transformar a sua epistemologia, as suas concepções acerca de como o conhecimento científico é construído [...] a epistemologia espontânea dos professores inclui muitas distorções e reduções adquiridas acriticamente pela impregnação social, o que impede uma orientação correcta do ensino das Ciências [...].

No sentido etimológico, epistéme significa ciência, verdade, e logos significa estudo, discurso. Desse modo, podemos definir epistemologia como sendo o estudo ou discurso sobre a ciência em busca de respostas para perguntas do tipo: O que conhecemos? Como conhecemos? O que é o conhecimento científico? O que faz a ciência? A epistemologia pode ser analisada sob dois prismas. Um segue o viés da filosofia ou história da ciência. Nesse caso, as pesquisas se concentram no estudo crítico das caminhadas, das dificuldades, das evoluções e das rupturas da ciência. A segunda visão procura compreender os papéis do sujeito e do objeto na construção do conhecimento. Essas duas vertentes são complementares. Por exemplo, saber como um cientista explicava a queda dos corpos há dois mil anos auxilia na compreensão que uma criança tem desse fenômeno atualmente. Por outro lado, entender como a criança encadeia os argumentos que embasam a sua concepção ajuda na análise histórica do fenômeno (CARVALHO, 1992; MARTINS, 2006). 
Segundo Becker (2012a; 2012b; 2013), há três maneiras de um professor conceber os papéis do sujeito e do objeto na construção do conhecimento, a saber: empirista, apriorista ou construtivista. A que mais se sobressai é a empirista, que acaba refletindo em práticas pedagógicas, excessivamente expositivas, apostando em uma transferência mecânica do conhecimento para os alunos, como se a aprendizagem pudesse acontecer por osmose. Geralmente, são escolhidas atividades focadas na memorização e na repetição, deixando os estudantes passivos nos processos de ensino e aprendizagem. Nesse caso, podemos afirmar que, quando um professor assume uma postura empirista ao ensinar, são mínimas as chances de alguma capacidade de pensamento crítico ser mobilizada ou desenvolvida (SASSERON; CARVALHO, 2013; 2014; SCARPA; SASSERON; SILVA, 2017). Não encontramos nenhuma pesquisa que defenda o contrário, mesmo que o material didático tenha sido construído, intencionalmente, com esse objetivo.

Contudo, mesmo sendo a minoria, há professores que adotam uma postura construtivista ao ensinar (BECKER, 2012b, 2013). Em uma perspectiva construtivista, as ações desses docentes buscam levar

[...] os estudantes a construir o seu conteúdo conceitual participando do processo de construção e dando oportunidade de aprenderem a argumentar e exercitar a razão, em vez de fornece-Ihes respostas definitivas ou impor-Ihes seus próprios pontos de vista transmitindo uma visão fechada das ciências. (CARVALHO, 2009, p. 3, grifo nosso)

Ou seja, para que uma prática pedagógica, exercida pelo professor, seja considerada construtivista, é necessário verificar se ela oportunizou ao aluno uma vivência ativa nos processos de ensino e aprendizagem, se, durante as aulas o discente ficou "[...] dialogando, interagindo, elaborando hipóteses e criando soluções para problemas, desenvolvendo assim, certas capacidades como questionar, refletir e argumentar [...]" (RODRIGUES; COELHO; AQUINO, 2009, p. 578, grifo nosso).

É importante realçar, inclusive, que isso pode acontecer, sem ter que ser banida a aula expositiva como estratégia didática (SCARINCI; PACCA, 2005). Desse modo, quando um professor assume uma comprovada postura construtivista ao ensinar, há uma probabilidade elevada de alguma capacidade de pensamento crítico ser mobilizada ou desenvolvida (SASSERON; CARVALHO, 2013; 2014; SCARPA; SASSERON; SILVA, 2017). É difícil de acreditar que isso não aconteça, pelo simples 
fato de o material didático não ter sido construído, intencionalmente, com esse objetivo. O que não pode ser confundido é o discurso com a prática docente, como constatou Becker (2012b; 2013) em suas pesquisas, ao mostrar que a maioria dos professores apresentou um discurso construtivista, mas conduz as suas ações didáticas com uma postura empirista. É dessa forma que entendemos a fala abaixo:

Apesar de muitos professores revelarem alguma relutância em assumir que as suas
práticas de ensino se caracterizam, sobretudo, pela transmissão de largos
repertórios de factos e rotinas, isso é, esmagadoramente, o que acontece nas salas
de aula. Alguns docentes tendem a considerar que o pensamento crítico está
presente nas suas aulas quando, na verdade, não está. Muitos acreditam que
desenvolvem capacidades de pensamento por falarem sobre a importância do
pensar e por solicitarem aos alunos que o façam. Mas uma capacidade de
pensamento não pode [sic] ser desenvolvida pelo facto de se falar sobre ela. Apesar
de, por vezes, os docentes ordenarem aos alunos que pensem, não há nada no
ambiente de aprendizagem que os ajude e encoraje a fazê-lo. (TENREIRO-VIEIRA E
VIEIRA, 2014, p. 23, grifo nosso)

Os resultados encontrados por Tenreiro-Vieira e Vieira (2013) mostram que há diferenças estatisticamente significativas no nível do pensamento crítico "entre os estudantes, futuros professores, sujeitos a estratégias de ensino orientadas para o ensino do pensamento crítico e os submetidos a estratégias sem essa orientação explícita [...]" (TENREIRO-VIEIRA; VIEIRA, 2013, p. 3689). Nesse contexto, por tudo que já foi exposto, há que se questionar se esses resultados podem ser generalizados para quaisquer posturas epistemológicas que o professor adotar nas suas ações didáticas.

Afinal, o que é imprescindível para fomentar o pensamento crítico dos alunos? Uma postura epistemológica comprovadamente construtivista por parte do professor, orientando as suas ações didático-pedagógicas ${ }^{2}$ ? Ou recursos didáticos e estratégias de ensino planejadas de forma intencional, sistemática e continuada para o cumprimento desse objetivo, concepção explicitada por Barreto (2019), mas que também é defendida pelos demais trabalhos que analisamos? Ficamos com a primeira alternativa, até sermos convencidos do contrário, por meio de pesquisas que levem em conta essas duas variáveis. Por enquanto, a nossa posição é de que:

[...] uma simples mudança de concepção epistemológica não garante, necessariamente, uma mudança de concepção pedagógica ou de prática escolar, mas sem essa mudança de concepção, superando o empirismo e o apriorismo, certamente não haverá mudança profunda na teoria e na prática de sala de

\footnotetext{
2 Como defendem Becker (2012a; 2012b; 2013), Carvalho e Gil-Pérez (2011), Gil-Pérez et al. (2005); Sasseron e Carvalho (2013; 2014), Scarpa, Sasseron e Silva (2017), entre outros pesquisadores da linha do construtivismo.
}

Revista Educação Online, Rio de Janeiro, n. 37, mai-ago 2021, p. 137-152 
aula. A superação do apriorismo e, sobretudo, do empirismo é condição necessária, embora não suficiente, de avanços apreciáveis e duradouros na prática docente. (BECKER, 2012a, p. 118, grifo nosso)

\section{Considerações finais}

A principal motivação da pesquisa, que originou este artigo, foi tomar conhecimento dos procedimentos metodológicos mais utilizados nas pesquisas nacionais, no ensino de ciências, que têm por objetivo apelar às capacidades de pensamento crítico dos alunos. Ao final, junto com a resposta de nossa indagação, percebemos que os trabalhos analisados não contemplam em suas reflexões, de modo adequado, o importante papel exercido pela postura epistemológica do professor, ao planejar, elaborar e aplicar as estratégias didático-pedagógicas.

O protagonismo dos processos de ensino e aprendizagem, voltados para a mobilização das capacidades de pensamento crítico dos alunos, está na utilização da taxonomia de Ennis (1985; 1987), o que consideramos um sério equívoco. É preciso que os pesquisadores da área de ensino de ciências reflitam sobre isso, pois não podemos confundir ações didáticas favoráveis ao apelo e desenvolvimento das capacidades de pensamento crítico, o que inclui tudo aquilo que já foi produzido pelas pesquisas de cunho construtivista, com os métodos e técnicas para identificar e mensurar essas capacidades. Caso contrário, corremos o risco de ressuscitar, para o ensino de ciências, a "máquina de ensinar" de Skinner (1972) 3 .

Por fim, como sugestão para trabalhos futuros sobre pensamento crítico, recomendamos que se dê preferência, na análise, ao tripé: materiais didáticos, aluno e intervenção docente (ao longo das aulas).

\section{Referências bibliográficas}

BARDIN, L. Análise de conteúdo. Lisboa: Edições 70, 1977.

BARRETO, J. V. Jogo simulador de papel como estratégia mobilizadora das capacidades do pensamento crítico. Dissertação (Mestrado em Ensino de Ciências e Matemática) - Programa de Pós-Graduação em Ensino de Ciências e Matemática, Universidade Federal de Sergipe, São Cristóvão, 2019.

\footnotetext{
3 Instruções do próprio Skinner, disponível em:

<https://www.youtube.com/watch?v=EXR9Ft8rzhk\&t=0>. Acesso em: 12 mar. 2021.
}

Revista Educação Online, Rio de Janeiro, n. 37, mai-ago 2021, p. 137-152 
BECKER, F. Educação e construção do conhecimento. $2^{\mathrm{a}}$ ed. Porto Alegre: Artmed, 2012a.

BECKER, F. Epistemologia do professor de matemática. Petrópolis: Vozes, 2012b.

BECKER, F. Epistemologia do professor; o cotidiano da escola. 16 ed. Petrópolis: Vozes, 2013.

BERTOLDO, T. A. T. Roda de conversa como estratégia promotora de capacidades de pensamento crítico. Dissertação (Mestrado em Ensino de Ciências e Matemática) - Programa de Pós-Graduação em Ensino de Ciências e Matemática, Universidade Federal de Sergipe, São Cristóvão, 2018.

BORDONI, A. J. et al. Reflexões acerca do uso do termo pensamento crítico em trabalhos publicados nos anais do X ENPEC. In: ENCONTRO NACIONAL DE PESQUISA EM EDUCAÇÃO EM CIÊNCIAS, 11., 2017, Florianópolis. Anais... Florianópolis: XI ENPEC, 2017. p. 1-8.

BOSZKO, C.; GÜLLICH, R. I. C. Estratégias de ensino de ciências e a promoção do pensamento crítico em contexto brasileiro. Revista Brasileira de Ensino de Ciências e Matemática, Passo Fundo, v. 2, n. 1, p. 53-71, 2019.

BRASIL. Lei de Diretrizes e Bases da Educação Nacional. ed. atual. até mar. de 2017. Brasília: Senado Federal, Coordenação de Edições Técnicas, 2017.

CARVALHO, A. M. P. Construção do conhecimento e ensino de ciências. Em Aberto, Brasília, v. 11, n. 55, p. 9-16, 1992.

CARVALHO, A. M. P .Critérios estruturantes para o ensino de ciências. In:

CARVALHO, A. M. P. de (Org.). Ensino de ciências: unindo a pesquisa e a prática. São Paulo: Cengage Learning, 2009. p. 1-17.

CARVALHO, A. M. P.; GIL-PÉREZ, D. Formação de professores de ciências: tendências e inovações. São Paulo: Cortez, 2011.

DELIZOICOV, D.; ANGOTTI, J. A.; PERNAMBUCO, M. M. C. A. Ensino de ciências: fundamentos e métodos. São Paulo: Cortez, 2002

ENNIS, R. H. A logical basis for measuring critical thinking skills. Educational Leadership, Alexandria, v. 43, n. 2, p. 44-48, 1985.

ENNIS, R. H. A taxonomy of critical thinking dispositions and abilities. In: BARON, J. B.; STERNBERG, R. J. (Ed.). Teaching thinking skills: theory and practice. New York: W. H. Freeman, 1987. p. 9-26.

ENNIS, R. H. Critical thinking across the curriculum. Inquiry: Critical Thinking Across the Disciplines, Montclair, v. 28, n. 2, p. 25-52, 2013.

GIL-PÉREZ, D. et al. Defesa do construtivismo: que entendemos por posições construtivistas na educação em ciência? In: CACHAPUZ, A. et al. A necessária renovação do ensino das ciências. São Paulo: Cortez, 2005. p. 109-126.

MARTINS, R. A história das ciências e seus usos na educação. In: SILVA, C. C. (Ed.). Estudos de história e filosofia das ciências: subsídios para aplicação no ensino. São Paulo: Livraria da Física, 2006. p. XXI-XXXIV.

MINAYO, M. C. S. O desafio do conhecimento: pesquisa qualitativa em saúde. 7. ed. São Paulo: Hucitec, 2000. 
PINHEIRO, H. B. Definição operacional [online]. Disponível em: <https://www.ime.unicamp.br/ hildete/oper.pdf>. Acesso em: 23 out. 2020.

RODRIGUES, C. R.; COELHO, S. M.; AQUINO, A. S. Ensino de física nas séries iniciais: um estudo de caso sobre formação docente. Caderno Brasileiro Ensino de Física, Florianópolis, v. 26, n. 3, p. 575-608, 2009.

SALVADOR, A. D. Métodos e técnicas de pesquisa bibliográfica. 9a ed. Porto Alegre: Editora Sulina, 1981.

SANTANA, E. M. Relação entre as capacidades do pensamento crítico e o desempenho dos estudantes de Química no Enade. Dissertação (Mestrado em Ensino de Ciências e Matemática) - Programa de Pós-Graduação em Ensino de Ciências e Matemática, Universidade Federal de Sergipe, São Cristóvão, 2018.

SANTANA, D. A. S. Capacidades de pensamento crítico: construção e validação de um instrumento de avaliação. Dissertação (Mestrado em Ensino de Ciências e Matemática) - Programa de Pós-Graduação em Ensino de Ciências e Matemática, Universidade Federal de Sergipe, São Cristóvão, 2019.

SANTIAGO, O. P. Perspectivas da abordagem ciência, tecnologia e sociedade e suas relações com as capacidades de pensamento crítico. Dissertação

(Mestrado em Ensino de Ciências e Matemática) - Programa de Pós-Graduação em Ensino de Ciências e Matemática, Universidade Federal de Sergipe, São Cristóvão, 2018.

SANTOS, F. C. Atividades investigativas e história da ciência: tendências em potencial para promover o pensamento crítico. Dissertação (Mestrado em Ensino de Ciências e Matemática) - Programa de Pós-Graduação em Ensino de Ciências e Matemática, Universidade Federal de Sergipe, São Cristóvão, 2018.

SASSERON, L. H.; CARVALHO, A. M. P. Ações e indicadores da construção do argumento em aula de ciências. Ensaio: Pesquisa em Educação em Ciências, Belo Horizonte, v. 15, n.2, p. 169-189, 2013.

SASSERON, L. H.; CARVALHO, A. M. P. A construção de argumentos em aulas de ciências: o papel dos dados, evidências e variáveis no estabelecimento de justificativas. Ciência \& Educação, Bauru, v. 20, n. 2, p. 393-410, 2014.

SCARINCI, A. L.; PACCA, J. L. Construtivismo na sala de aula: concepções dos professores sobre a função da aula expositiva. In: ENCONTRO NACIONAL DE PESQUISA EM EDUCAÇÃO EM CIÊNCIAS, 5., 2005, Florianópolis. Atas... Bauru: ABRAPEC, 2005. p. 1-12.

SCARPA, D. L.; SASSERON, L. H.; SILVA, M. B. O ensino por investigação e a argumentação em aulas de ciências naturais. Tópicos Educacionais, Recife, v. 23, n.1, p.7-27, 2017.

SILVA, I. M. A aprendizagem baseada em problemas: uma análise da implementação na disciplina de tecnologia da informação e comunicação no ensino de química. Tese (Doutorado em Ensino das Ciências) - Programa de PósGraduação em Ensino das Ciências, Universidade Federal Rural de Pernambuco, Recife, 2017.

SKINNER, B. F. Tecnologia do ensino. São Paulo: Ed. da Universidade de São Paulo, 1972. 
SOUSA, A. S.; VIEIRA, R. M. O pensamento crítico na educação em ciências: revisão de estudos no ensino básico em Portugal. Rev. Fac. Educ. Cáceres, v. 26, n. 1, p. 15-33, 2018.

SOUZA, R. S. B. Possíveis contribuições de atividades investigativas para o desenvolvimento de capacidades do pensamento crítico. Dissertação (Mestrado em Ensino de Ciências e Matemática) - Programa de Pós-Graduação em Ensino de Ciências e Matemática, Universidade Federal de Sergipe, São Cristóvão, 2019.

TENREIRO-VIEIRA, C. O pensamento crítico na educação científica: proposta de uma metodologia para a elaboração de actividades curriculares. Dissertação (Mestrado em Educação) - Faculdade de Ciências, Universidade de Lisboa, Lisboa, 1994.

TENREIRO-VIEIRA, C. O pensamento crítico na educação científica. Lisboa, Instituto Piaget, 2000.

TENREIRO-VIEIRA, C.; VIEIRA, R. M. Promover o pensamento crítico dos alunos: propostas concretas para a sala de aula. Porto Editora: Porto, 2000.

TENREIRO-VIEIRA, C.; VIEIRA, R. M. Estratégias de ensino e aprendizagem e a promoção de capacidades de pensamento crítico. In: CONGRESO

INTERNACIONAL SOBRE INVESTIGACIÓN EN DIDÁCTICA DE LAS CIENCIAS ANAIS, 9., 2013, Girona. Anais... Girona: Universidade de Girona, 2013. p. 36853690.

TENREIRO-VIEIRA, C.; VIEIRA, R. M. Construindo práticas didático-pedagógicas promotoras da literacia científica e do pensamento crítico. In: DOCUMENTOS de trabajo de lberciencia. Madrid: Iberciencia, 2014. N. 02. 